\title{
Safety performance assessment of food industry facilities using a fuzzy approach
}

\author{
F. Barreca, G. Cardinali, C.R. Fichera, L. Lamberto, G. Modica \\ Dipartimento di Agraria, Università degli studi Mediterranea di Reggio Calabria, Reggio Calabria, \\ Italy
}

\begin{abstract}
The latest EU policies focus on the issue of food safety with a view to assuring adequate and standard quality levels for the food produced and/or consumed within the EC. To that purpose, the environment where agricultural products are manufactured and processed plays a crucial role in achieving food hygiene. As a consequence, it is of the utmost importance to adopt proper building solutions which meet health and hygiene requirements and to use suitable tools to measure the levels achieved. Similarly, it is necessary to verify and evaluate the level of safety and welfare of the workers in their working environment. The safety of the workers has not only an ethical and social value but also an economic implication, since possible accidents or environmental stressors are the major causes of the lower efficiency and productivity of workers. However, the technical solutions adopted in the manufacturing facilities in order to achieve adequate levels of safety and welfare of the workers are not always consistent with the solutions aimed at achieving adequate levels of food hygiene, even if both of them comply with sectoral rules which are often unconnected with each other. Therefore, it is fundamental to design suitable models of analysis that allow assessing buildings as a whole, taking into account both health and hygiene safety as well as the safety and welfare of workers. Hence, this paper proposes an evaluation model that, based on an established study protocol and on the application of a fuzzy logic procedure, allows evaluating the global safety level of a building. The
\end{abstract}

Correspondence: Francesco Barreca, Dipartimento di Agraria, Università degli studi Mediterranea di Reggio Calabria. Località Feo di Vito, 89122 Reggio Calabria, Italy.

Key words: Safety Performance Assessment, Agri-food industry facilities, Post Occupancy Evaluation (POE), Global Safety Buildings Index (GSBI), Fuzzy sets.

Acknowledgements: this research was partly funded by the QUASIORA (Quality Safety Origin of the food), which was granted within the Framework Program "APQ Ricerca Scientifica e Innovazione Tecnologica nella Regione Calabria" (Scientific Research and Technological Innovation in the Calabria Region) involving the European Union, the Calabria Region and the Italian Ministry for Education, University and Research.

(C) Copyright F. Barreca et al., 2013

Licensee PAGEPress, Italy

Journal of Agricultural Engineering 2013; XLIV(s2):e58

doi:10.4081/jae.2013.s2.e58

This article is distributed under the terms of the Creative Commons Attribution Noncommercial License (by-nc 3.0) which permits any noncommercial use, distribution, and reproduction in any medium, provided the original author(s) and source are credited. proposed model allows to obtain a synthetic and global value of the building performance in terms of food hygiene and safety and welfare of the workers as well as to highlight possible weaknesses. Though the model may be applied in either the design or the operational phase of a building, this paper focuses on its application to certain buildings already operational in a specific productive context.

\section{Introduction}

Recent statistical surveys show that, in Europe (European Commission, 2007), food manufacturing companies are about 310.000 and workers in the sector are over 4.688.000, for an annual turnover of over 850 billion Euros. These figures give an idea of the importance of this productive sector and, above all, of its significance for the whole European economy. On the other hand, consumers demand more and more guarantees of safety and sustainability of the entire chain of production.

In order to ensure suitable health and hygiene standards, it is fundamental to consider the whole manufacturing cycle in all types of agri-food companies: from the supply of raw material to the sale of the product. In fact, during all the phases of its manufacture, the product risks of being contaminated by pathogenic microorganisms for reasons related not only to the productive process but also to the indoor environmental conditions of hygiene of the manufacturing facility, which are strictly connected with the adopted technical and management solutions (Lelieveld H.L.M., et al., 2005).

However, agri-food facilities must assure not only the consumers' hygiene safety, by adopting all the precautions and building solutions which may ensure adequate safety levels for product contamination, but also an adequate safety level for workers (Sinisammal J. et al.; 2012). Recently, EU-27 has implemented the European strategy on health and safety at work for the period 2007-2012 ("Improving quality and productivity at work: Community strategy 2007-2012 on health and safety at work") establishing six intermediate objectives in order to achieve a $25 \%$ reduction in the total incidence rate of accidents at work. As recently reported, the Strategy has met this ambitious goal. Currently, the Health and Safety Strategy for the period 2013-2020 is under implementation.

Therefore, productive facilities must ensure adequate performances in terms of health and hygiene standards and of workers' safety (Jacinto C.et al., 2009). These performances must be carefully taken into account during the building design process and regularly verified during its use. To that purpose, Post Occupancy Evaluation (POE) (Joon-Hoa et al. 2012) is particularly important. Another significant aspect to consider is that the building performances may also depend on how the manufacturing process is managed and conducted (Leppälä 2012). For instance, hygiene conditions are influenced by sanitation procedures as well as the noise level is strictly connected with the machines, plants and operation modes used (Parejo-Moscoso 
et al.2013). One of the main goals of this paper is to obtain a synthetic value of global safety that can be referred exclusively to the building (Fabiano et al.2004) and to its components and plants. Specifically, this paper proposes a model for the evaluation of the Global Safety Building Index (GSBI), which is based only on the evaluation of the performances of the technical elements and of the plants of the building and does not take into account the contingent conditions of the manufacturing process and, therefore, the company operation modes (Stave and Törner 2007). This approach allows applying the model also in the design phase and evaluating the global safety level of the building even before it starts operating. Thus, the model highlights the most important weaknesses in global safety and verifies the effects of possible interventions and corrections.

\section{Materials and Methods}

\section{The model for the evaluation of the Global Safety Buildings Index}

The building system evaluation, encapsulated through the Global Safety Buildings Index (GSBI), is carried out by means of specific performance indicators. Such indicators can be measured either objectively, through an instrumental survey, or subjectively, through a qualitative judgment expressed by an expert surveyor.

GSBI set of indicators was organized into a four-level tree structure (Figure 1). In particular, the first level was divided into the two established safety categories: workers' safety and hygiene safety. This hier-

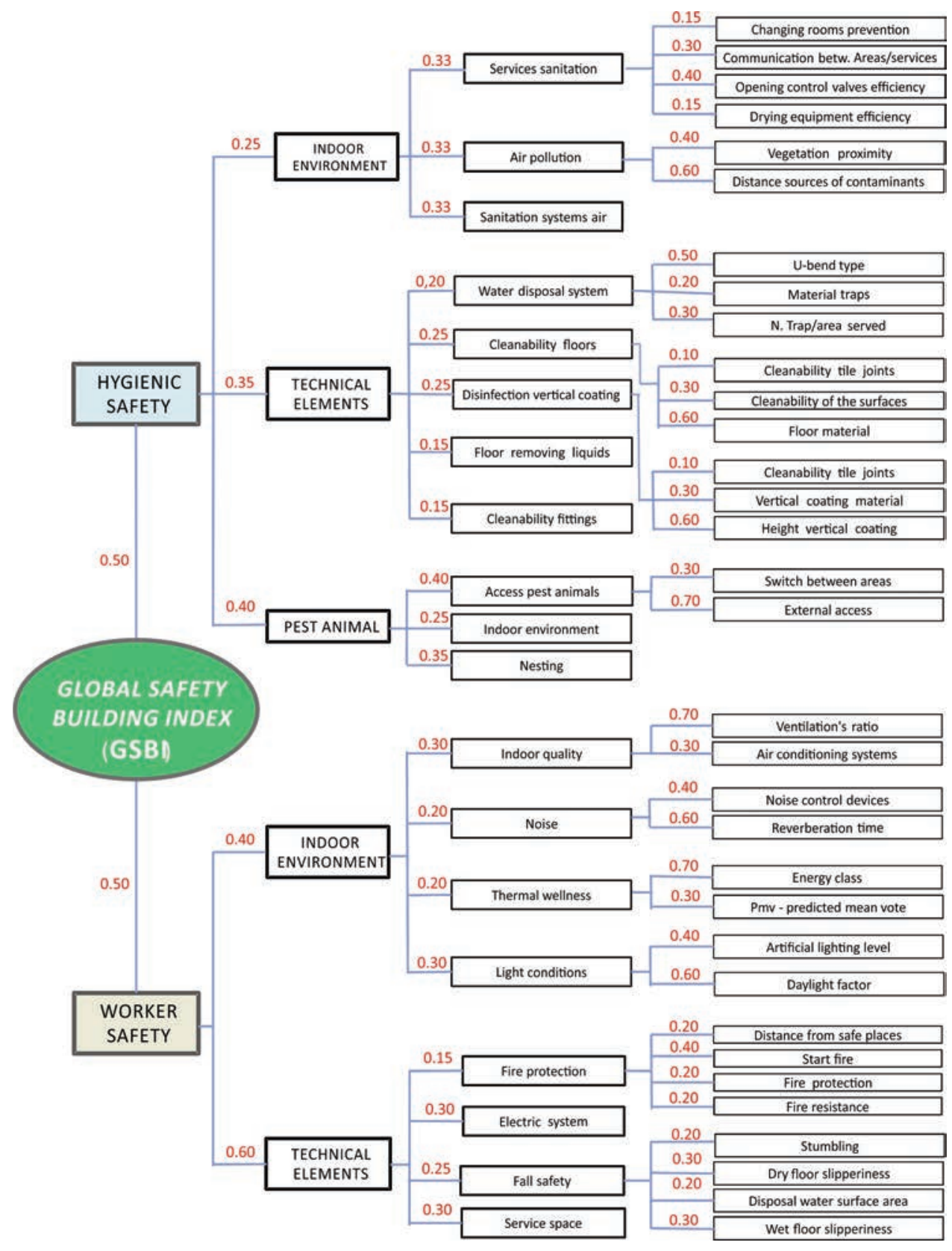

Figure 1. Chart showing the hierarchical structure of the model for the evaluation of the Global Safety Buildings Index (GSBI). For each indicator, the relative weight $[0,1]$ corresponding to each hierarchical level, is reported. 
archization allows evaluating each category separately, thus showing in which category the building may reveal greater weaknesses. For each category on the second hierarchical level, evaluation was carried out on the adequacy of the technical system (building components which are directly related to safety) and on the environment safety (referred to the performances of the class of the technical elements that indirectly contribute to creating internal environmental and functional conditions that enhance safety).

\section{Set of quantitative and qualitative indicators}

On the basis of their different typology, selected indicators were distinguished in quantitative and qualitative indicators. Quantitative indicators are characteristics of the building that can be instrumentally measured or evaluated through calculation procedures; while qualitative indicators are based on the judgment of a surveyor/assessor. For instance, in the category of workers' safety, the slip, trip and fall safety of the building was evaluated. The risks of slipping and tripping are among the main risk factors for workers in the agri-food sector. The loss of grip between foot and floor may be induced either by an inadequate value of floor roughness or by the presence of liquids that alter the surface of the material, or by both conditions. A useful element to quantify the workers' risk of slipping is the measurement of the coefficient of sliding friction between sole and floor (Malkin and Harrison 1980). The proposed model evaluates fall safety by referring to the following specific indicators: slipping on wet and dry floor; tripping due to loss of balance; quick liquid removal from the floor. In this case, indicators are evaluated by referring to instrumental measurements. For instance, slip safety is evaluated by measuring slipperiness with the Tortus method, which was developed by Malkin and Harrison at British Ceramic Research Association (1980) and is based on the measurement of the sliding friction value of a slipping element (in rubber for wet floors and in leather for dry floors). Slipperiness is measured by means of a Tortus digital tribometer FSC 2011 (Figure 2).

\section{Data analysis and aggregation}

The numerical analysis and the aggregation of the values of the qualitative and quantitative indicators were carried out by means of fuzzy logic (Beriha et al. 2012).

The main property of fuzzy logic (Zadeh 1965) is that it translates the linguistic judgments, expressed by man in a vague and inaccurate manner, into numerical and mathematical terms. Therefore, the use of this logic allows overcoming the uncertainty of the qualitative evaluation of the single building technical element, conducted by a surveyor, as well as considering the difficulty in estimating how the performance of each component contributes to the value of the global safety of the building (Pinto et al. 2012). Furthermore, the standardization of values in hierarchical levels allows expressing GSBI in a variable interval between 0 and 1 , where 0 corresponds to the worst value while 1 corresponds to the best one. In the implemented model, the values of indicators were transformed into fuzzy membership values by using a specific transformation function of triangular type that takes into account three levels of judgment. For instance, in the case of slip safety, safety is very low if the coefficient of sliding friction is below 0.4 ; it is acceptable if the coefficient is between 0.4 and 0.74 ; and, finally, it is good if the coefficient is above 0.74 . The aggregation of the four levels composing the hierarchical model was carried out on the elements belonging to the same hierarchical level by means of a normalized fuzzy weighted average procedure. The weights of each level of evaluation, whose sum was equal to 1 (Figure 1), were defined with a group of field experts. In particular, the relative weight of each element was defined in relation to its contribution to global safety, to the level of measurement accuracy, to the adopted measurement method (instrumental or subjective), to literature data, to the acquired scientific knowledge and to the values of National and international regulations.

\section{Results}

The validation of the model required the development of a specific procedure (Figure 3). Such a procedure includes consecutive steps

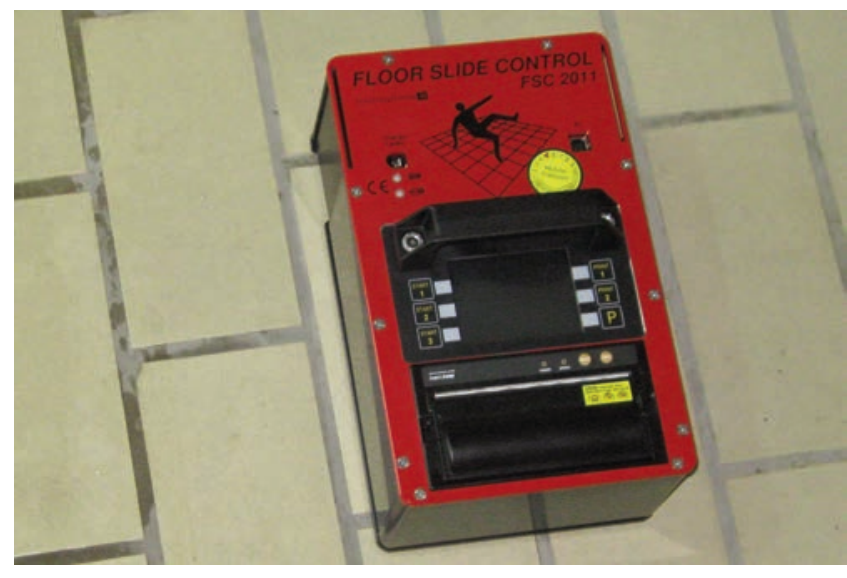

Figure 2. Survey of coefficient of friction on the floor by the Tortus digital tribometer FSC 2011.

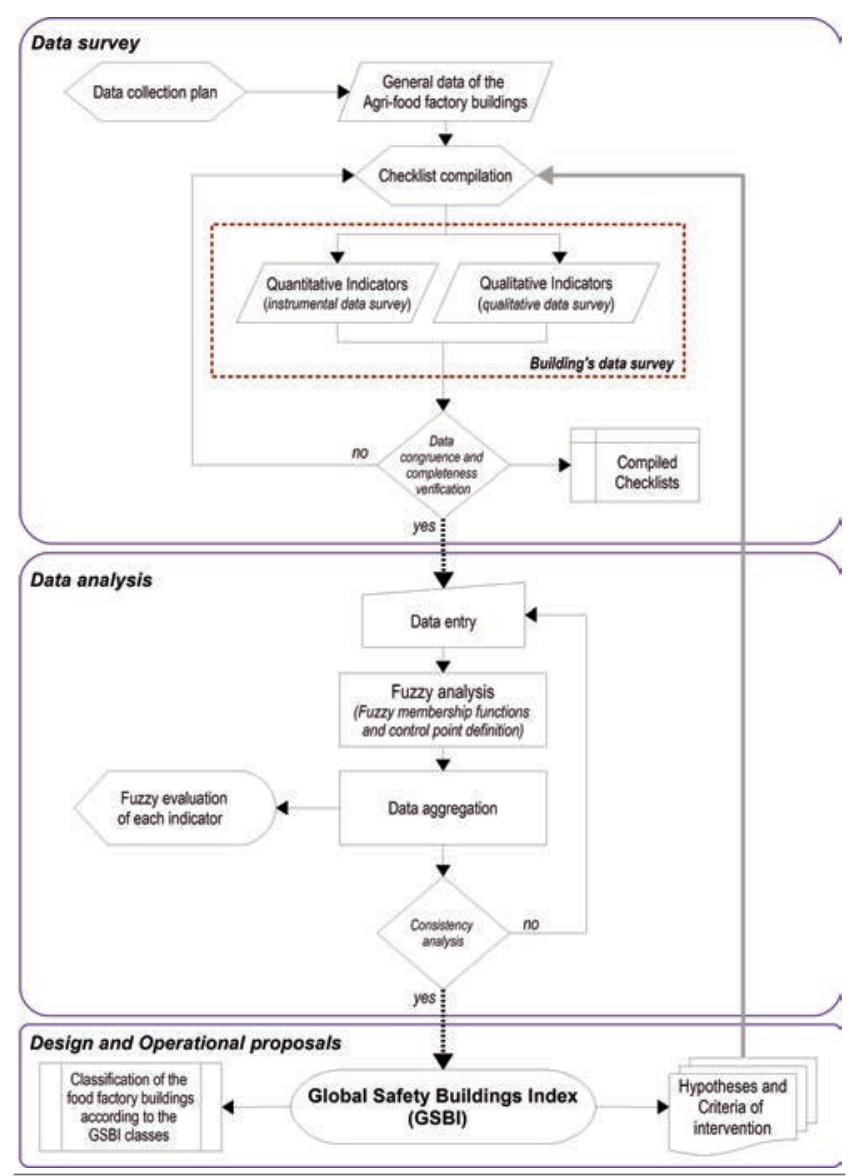

Figure 3. Flow-chart of the procedure for the evaluation of the Global Safety Buildings Index (GSBI). 
that, in each phase, allow checking proper progress and making corrections.

In particular, such steps can be summarized as follows:

- Planning of the survey campaign and preliminary investigation of the manufacturing facility, preliminary building survey.

- Collection of data on the company that uses the building and on its organization.

- Recording and acquisition of detailed data and performance evaluation of the building and of its components through instrumental measurements and evaluation judgments expressed by the surveyor and organized according to a specially prepared checklist.

- Data analysis and verification of the congruency of recorded data and measures with the performance specifications of the elements.

- Compilation of the checklist and filling in of a survey form.

- Input of the acquired data in the analysis model and transformation of data into fuzzy values.

- Implementation of the model of analysis and aggregation of the different hierarchical levels through established weight functions.

- Verification of the consistency of the results obtained from the model and possible adjustment and improvement of data.

- Comparison and analysis of the results obtained from the model, observations on the results obtained in the different hierarchical levels of the model.

- Calculation of the Global Safety Building Index (GSBI) and of the relative values for each environmental unit and category.

- Analysis and identification of possible weaknesses in health and hygiene safety and in workers' safety.

- Development of possible proposals and corrections on the building in order to improve performances in the hygiene safety of products and in the workers' safety. (Figure3)

At this point, the application of the model may end or, starting a loop procedure from the initial phases of surveying, it may allow verifying the effectiveness of the corrections put in place or only envisaged.

This organization of the model allows evaluating the global safety level of the building or calculating it already during the phase of design. Moreover, it enables to verify the effectiveness of possible corrections or modifications in the technical elements of the buildings.

In addition, the possibility to compare the value of the building global safety and established benchmark values is particularly important.

The application of the whole procedure to a manufacturing area of a

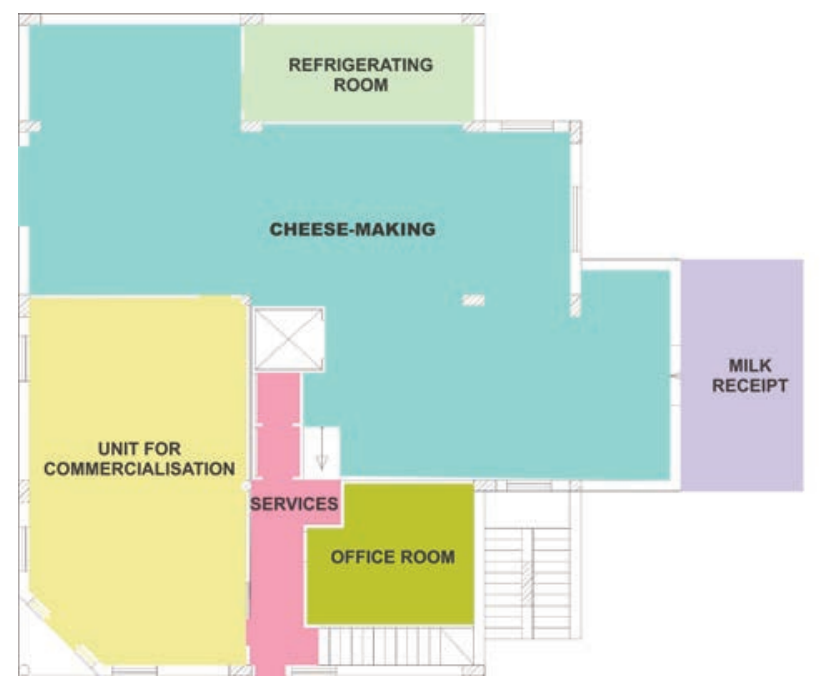

Figure 4. Lay-out of the surveyed dairy farm. dairy farm located in the plain of Gioia Tauro, Reggio Calabria, is described below.

The manufacturing facility covers two storeys, each of about $250 \mathrm{~m}^{2}$; the manufacturing area in on the ground floor and covers around 130 $\mathrm{m}^{2}$ (Figure 4).

After a first inspection, the building was surveyed and then, following the checklist, metrical data and judgments on the performance of the main building components, in terms of hygiene safety of the products and workers' safety, were acquired.

The values of the fuzzy functions obtained from the application of the proposed model (Figure 5) allowed carrying out a first series of analyses and evaluations on the safety level of the manufacturing area of the analyzed building. In particular, the geometric centre of the fuzzy function, which describes global safety calculated through the illustrated procedure, has a value (0.439) that is slightly lower than the average value $(0.50)$. This means that the global safety of the building is certainly acceptable, even if it shows further room for improvement. The disaggregate values of the centres of the functions related to the workers' safety and health and hygiene safety ( 0.439 and 0.644 respectively) are also close to the average value. The comparison between the two membership functions allows further considerations. In fact, the membership function of the workers' safety has a value of maximum membership equal to 0.565 , while the value of the membership function of the health and hygiene safety of the building is 0.725 , though it shows greater dispersion of values. This result shows that, though the global health and hygiene safety of the building (considering the geometric centre of the function) is lower than the workers' safety, it would be sufficient to act on a few negative causes of dispersion, and therefore on those technical elements showing the lowest efficiency judgment, to considerably improve the global value and, as a result, to increase the GSBI final value.

\section{Discussion and Conclusions}

The application of the proposed procedure allowed verifying not only if the developed model was correct but also if it was easy to apply. To that purpose, in the phase of the model definition, particular importance was given to the determination of the sets of indicators concern-

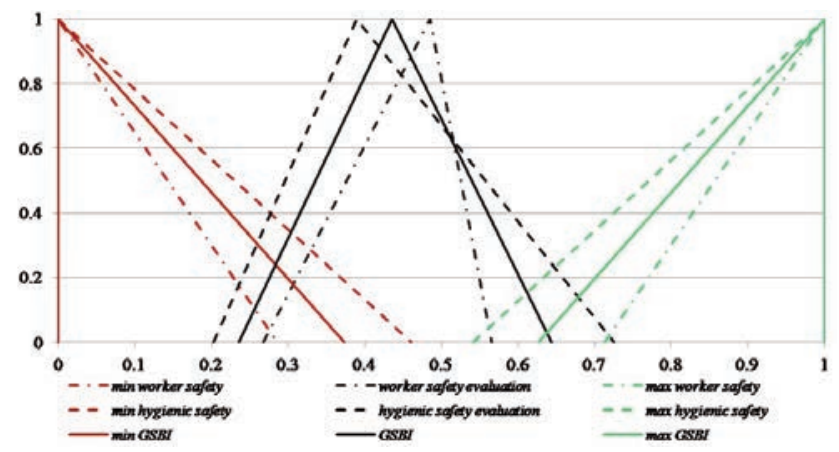

Figure 5. Graph showing the fuzzy membership function of the Worker Safety Evaluation (WSE), the Hygienic Safety Evaluation (HSE) and the Global Safety Buildings Index (GSBI). For each of these indexes, the minimum and the maximum values are reported. 
ing the hygiene safety of products and the workers' safety. Specifically, though indicators were limited in number to facilitate the phase of data acquisition and the application of the model, they were chosen according to the following characteristics:

- Being easy to assess by means of not particularly complex instruments;

- Being exclusively referred to technical building components;

- Being independent from contingent factors or from the boundary conditions of the manufacturing process;

- Being independent per environmental unit and field of evaluation.

In fact, the number of evaluation indexes must be adequate to describe the building performances correctly and quite accurately in relation to health and hygiene safety and workers' safety and must take into account current regulations and the most dangerous risks inside buildings. Finally, it is worth mentioning that the structure of the model allows necessary adjustments and improvements during all the phases of the process and it is so general that it may be applied to all types of agri-food production. Therefore, this paper will be further developed to allow its application to other functional fields of the manufacturing facility and to various types of production.

\section{References}

Abouelnaga A., Metwally A.,Aly N., Naguib A.; Nagy M., Agamy S. 2010. Assessment of nuclear energy sustainability index using fuzzy logic. Nuclear Engineering and Design, 240 (2010), pp.2820-2830.

Beriha G.S., Patnaik B., Mahapatra S., Padhee S. 2012. Assessment of safety performance in Indian industries using fuzzy approach. Expert Systems with Applications, 39(3), pp.3311-3323.

Joon-Hoa C., Vivianb L., Azizanb A. 2012. Post-occupancy evaluation of 20 office buildings as basis for future IEQ standards and guide- lines. Energy and buildings, 46 pp. 167-175.

European Commission, 2007. Community strategy on health and safety at work (2007-2012). Brussels. Available at: http://europa.eu/legislation_summaries/employment_and_social_policy/health_hygiene _safety_at_work/10114_en.htm\#

Lelieveld H.L.M., Mostert M.A., Holah J. 2005. Handbook of hygiene control in the food industry. 1th rev. ed Woodhead Publishing Limited, Cambridge,UK.

Fabiano B., Currò F., Pastorino R. 2004. A study of the relationship between occupational injuries and firm size and type in the Italian industry. Safety Science, 42(7), pp.587-600.

Jacinto C., Canoa M., Guedes Soares C. 2009. Workplace and organisational factors in accident analysis within the Food Industry. Safety Science, 47(5), pp.626-635.

Leppälä J.M.. 2012. Integrated production and safety risk management on. Proc. International Conference of Agricultural Engineering, Valencia, Spain, July 8-12.

Malkin F., Harrison R. 1980. A small mobile apparatus for measuring the coefficient of friction of floors. Journal of Physics D: Applied Physics, 13, pp.77-79.

Parejo-Moscoso J.M., Rubio-Romero J.C.,Pérez-Canto S., SorianoSerrano M. 2013. Health and safety management in olive oil mills in Spain. Safety Science, 51(1), pp.101-108.

Pinto, A., Ribeiro R., Nunes L. 2012. Fuzzy approach for reducing subjectivity in estimating occupational accident severity. Accident; analysis and prevention, 45, pp.281-90.

Sinisammal J., Belt P., Härkönen J., Möttönen M.,Väyrynen S. 2012. Managing Well-Being at Work during 2010 - Expert Viewpoints. Open Journal of Safety Science and Technology, 2, pp.25-31.

Stave C., Törner M. 2007. Exploring the organisational preconditions for occupational accidents in food industry: A qualitative approach. Safety Science, 45(3), pp.355-371.

Zadeh L.A. 1965. Fuzzy sets. Information and Control, 8, pp. 338 